\title{
Influences of perinatal conditions on adult body size and intellectual performance: a register-based cohort study
}

\author{
Martha Gunn Eide \\ Section for Epidemiology and Medical Statistics, Department of Public Health and Primary Health Care and \\ Medical Birth Registry of Norway, Locus of Registry Based Epidemiology, University of Bergen, Norway \\ E-mail: martha.eide@mfr.uib.no Telephone:+475558 8523
}

\section{INTRODUCTION}

In perinatal epidemiological research, mortality has been a central outcome. Compared to later periods in life, perinatal mortality has been, and still is, considerable. However, as perinatal mortality has decreased to a gratifying extent, perinatal and neonatal morbidity, as well as long-term health outcomes and their possible perinatal origin have come into focus. The first period of life is increasingly thought to be important in the aetiology of adult health and disease. Recent evidence suggests that factors acting in foetal life, during critical periods of growth and development, may biologically 'programme' adult chronic disease. ${ }^{1,2}$ Later experiences may modify these effects. Hence, adult chronic disease may also reflect cumulative lifetime unhealthy exposures. ${ }^{3}$

Health in early adulthood may be regarded as an intermediate variable on a causal pathway between intrauterine influences and adult disease development. Thus, elucidating influences of perinatal conditions on health in early adulthood may provide a better understanding of the "web of causation" linking early life exposures and adult disease. This article is based on a doctoral thesis in preparation, and two of its papers ${ }^{4,5}$ from a nationwide historical cohort study. The study assesses possible associations between perinatal conditions on one hand and adult body size and intelligence on the other.

\section{Adult health}

Health measures may be viewed as intermediate variables in the relationship between early life exposures and adult disease outcomes. Height, weight, and intellectual performance may be regarded as anthropometric and functional measures of health.

\section{Height}

In Norway, as in most developed countries, mean height in adolescence and adulthood has been increasing through the last century. ${ }^{6,7}$ The increase in height is viewed as an expression of generally improved living conditions, including the general nutritional status of the population. ${ }^{7}$ Nutrition and infectious diseases in childhood are known to influence substantially adult height, ${ }^{3}$ although heritability is reported to account for more than $80 \%$ of the variation. ${ }^{8}$

There is a negative association between body height and mortality, and height has also been found to be predictive of cardiovascular morbidity and obstructive lung disease. ${ }^{9}$ These associations have been confirmed in several studies. ${ }^{10-13}$ The height-mortality association appears to be rather strong, incremental, consistent across a number of study populations, and independent of socioeconomic circumstances in both childhood and adult life. ${ }^{12}$ Waaler also reported that short stature was related to excess mortality from stomach and lung cancer. ${ }^{9}$ On the other hand, tallness has been shown to be associated with high rates of cancers of the breast, ovary, prostate, and kidney. ${ }^{3,14}$ In one study, tallness appeared to be associated with good self-perceived health. ${ }^{13}$

Since height reflects an individual's childhood nutrition and growth, as well as socioeconomic conditions, ${ }^{7}$ these findings may support the hypothesis that the early environment influences adult health. However, it has also been shown that tall stature is associated with better education and upward social mobility. ${ }^{15}$ Therefore, height may influence health through its effect on adult socioeconomic position. ${ }^{12}$ Other explanations for the positive association between stature and health may be a reverse pathway; that disease may lead to shorter height, or the possibility that genetic regulation of height and susceptibility to disease may be linked in some way, ${ }^{9}$ e.g by involving pleiotrophic genes.

\section{Weight}

Overweight and obesity are well known risk factors for poor adult health. There is an established association between excess body weight and overall mortality. ${ }^{16}$ Obesity is a risk factor for many chronic diseases, such as coronary heart disease, stroke, respiratory disease, several orthopaedic disorders, gallbladder disease, infertility, and type 2 diabetes. ${ }^{16-19}$ Obese women have a higher risk of obstetric complications. ${ }^{20}$ Furthermore, overweight is associated with increased risk of developing colorectal cancer and cancer of the endometrium in females..$^{17,19-21}$ Because age influences the risk, the 
relationship between breast cancer and body weight is unclear. However, at postmenopausal ages, high BMI is a risk factor for breast cancer. ${ }^{3,20,21}$

Mechanisms underlying the association between obesity and poor health may be of both biological and social origin. For example, elevated blood pressure, hyperlipidemia and altered haemostatic factors are effects of excess fatness that are implicated in the association between obesity and coronary heart disease, whereas endocrine effects are infertility and type 2 diabetes. ${ }^{20}$ However, being overweight may also have adverse socioeconomic consequences; it has been observed that fatter women are less likely to marry, have poorer job opportunities and lower incomes than other women. ${ }^{18}$ Similar but weaker trends have been found among men. Finally, a genetic mechanism linked to both obesity and poor health due to chronic disease is also plausible.

\section{Intelligence}

The intelligence quotient (IQ) represents an individual's intelligence test result in comparison to other people. The frequency distribution of IQ is Gaussian; the mean IQ is 100 and the SD is 15 . The construct of intelligence is extremely useful, and of great practical and social importance. ${ }^{22}$ In military services, intelligence tests have been used to allocate soldiers to various service branches.

Recently, intelligence as a determinant of health outcomes has attracted much research attention. Studies have linked intelligence in childhood to mortality in later life, ${ }^{23-26}$ although in one study the association was observed only in men. ${ }^{24}$ Further, intelligence is associated with a number of important health outcomes, including cardiovascular disease, ${ }^{25}$ suicide, ${ }^{27}$ and some cancers. $^{28}$ The association between intelligence and mortality is inverse and incremental, implying a risk gradient across the distribution of IQ scores. Thus, this relates to the general population, rather than only to those with severe intellectual impairment. Moreover, the relation of poor health with intelligence remains after adjustment for early life socioeconomic status (SES). ${ }^{23,24}$

Both social and genetic factors are likely to be important in determining the association between intelligence and health. Heritability of general intelligence is approximately $50 \%$ with estimates ranging from $40 \%$ to $80 \%$; i.e. genetic variation accounts for approximately half of the variance. ${ }^{29}$ High intelligence in childhood is likely to lead to educational success, well paid employment, and high social status; conditions that are strongly associated with later disease. ${ }^{26}$ High intelligence promotes faster and more complete learning, resulting in better preventive self-care and better compliance with medication instructions. ${ }^{30}$ For example, diabetes, hypertension and many other chronic illnesses, require self-monitoring and frequent judgments to keep physiological processes within safe limits.

\section{Perinatal conditions and adult health}

Until 1940, rates of all-cause mortality in children and young adults fell steeply in developed countries. ${ }^{3}$ This was mainly due to the decline in mortality from infectious diseases, as bacteriological research had dominated the public health interest. After World War II, mortality rates from coronary heart disease and lung cancer rose rapidly. ${ }^{3}$ Consequently, public health attention was shifted away from infectious disease and towards the aetiology of specific chronic diseases. It had been predicted that death rates in the middle-aged would begin to fall sharply as the cohorts who had experienced dramatic improvements in childhood survival during childhood reached this age. But apparently, health of adults worsened despite the improvements in child health. Therefore the search for aetiological factors focused on the adult environment and adult lifestyle, and risk factors like body size and various health behaviours were identified. Early life factors lost attention.

However, social and geographical variations in chronic disease risk could not simply be explained by the 'lifestyle model'. Interest in relations between early life and adult chronic disease was stimulated by findings that involved 'tracking' of risk factors such as blood pressure, cholesterol levels, and obesity from childhood to adult life.

In 1977, based on ecological analyses of official mortality statistics, the Norwegian researcher Anders Forsdahl hypothesized that poor living conditions in childhood and adolescence are important risk factors for coronary heart disease, as well as all-cause mortality. ${ }^{31}$ Poor childhood living conditions, particularly if followed by later affluence, were suggested as a possible mechanism. Thus, Forsdahl emphasized the accumulation of risk over the life course. Moreover, studies of adult height and adult mortality and morbidity provided support to the hypothesis that poor living conditions in childhood affects health in later life. ${ }^{9,12}$

More recently, research by David Barker and colleagues in Southampton, England, has gained much attention. Barker emphasized undernutrition during critical periods of development as the most important risk factor. Studies from his group have reported possible long-term associations between birth size and chronic adult diseases, such as coronary heart disease, stroke, respiratory disease, and type 2 diabetes, as well as intermediate conditions including hypertension, impaired lung function, and insulin resistance. ${ }^{1,32}$ From these findings the so-called 'foetal origins hypothesis' emerged during the 1990s. The hypothesis is based on the concept of 'programming', by which is meant a general process whereby a stimulus or insult at a critical period of development have lasting or lifelong significance. ${ }^{33}$ A critical period of development refers to a time window in which an exposure can have adverse (or protective) effects on development and subsequent 
morbidity. ${ }^{34}$ The Barker group has interpreted the findings by suggesting that nutrition in foetal and early life is crucial; i.e. under-nutrition during critical periods of development is an important environmental determinant of health in adult life. ${ }^{32}$

The term programming was first proposed by Alan Lucas in 1991. He initiated experimental studies to test the importance of early nutrition. ${ }^{33}$ Now programming is a well established biological concept, and, although most supporting evidence is derived from experimental studies in animals, the concept is biologically plausible. The effects of alterations in foetal nutrition may be direct, due to inadequate substrate availability, or indirectly mediated through endocrine hormonal effects. This may result in developmental adaptations with permanent changes in structure, physiology, and metabolism. Consequently, the individual may become susceptible to cardiovascular, metabolic or endocrine diseases later in life.

The increasing literature on early origins of adult disease during the 1980s and 1990s challenged the aetiological model for adult disease that emphasized adult risk factors. Up to date, long-term outcomes such as obesity, mental health and cognitive function, as well as some cancers, are increasingly being studied in the light of the foetal origins hypothesis.

Nevertheless, criticism has been raised towards the foetal origins hypothesis. The major objections regard study design, ${ }^{35}$ including loss-to follow-up, ${ }^{36,37}$ and possible confounding factors, of which the influence of socioeconomic conditions ${ }^{38}$ on adult health are the most important. ${ }^{36}$ Another major concern is the contributing roles of postnatal growth and development, and how interactions between foetal and postnatal life influence adult health. ${ }^{39,40}$ Furthermore, the role is increasingly questioned of genetic factors and the interaction of genetic and environmental factors on developmental processes associated with adult chronic disease risk. This criticism has lead to a change in focus towards a 'life course approach', 3 rather than only early life experiences, as the possible pathway. By studying physical or social exposures during pregnancy, childhood, adolescence, through adulthood, life course epidemiology is aimed at elucidating biological, behavioural, and psychological processes underlying longterm effects on health and disease risk.

The influence of perinatal conditions on adult health may be exerted trough different pathways. ${ }^{34}$ Figure 1 illustrates four pathways between poor intrauterine growth and adult health. First, poor intrauterine growth may lead to impaired brain development which in turn has adverse effects on intellectual performance resulting in inefficient information processing in the central nervous system and poor health in adulthood (I). Second, adverse childhood SES may have influences on educational attainment and thus on adult SES (II). Third, adverse childhood SES may be associated with poor nutrition and environmental hazards in childhood leading to increased risk of childhood illness and subsequently poor intellectual performance (III). Fourth, childhood illness may result in adverse educational attainment and lower adult SES (IV). In addition, genetic factors may affect intrauterine growth, intellectual performance, and health and disease later in life.

The perinatal conditions associated with adult health outcomes of specific interest in this article are birth size, gestational age, and breech birth.

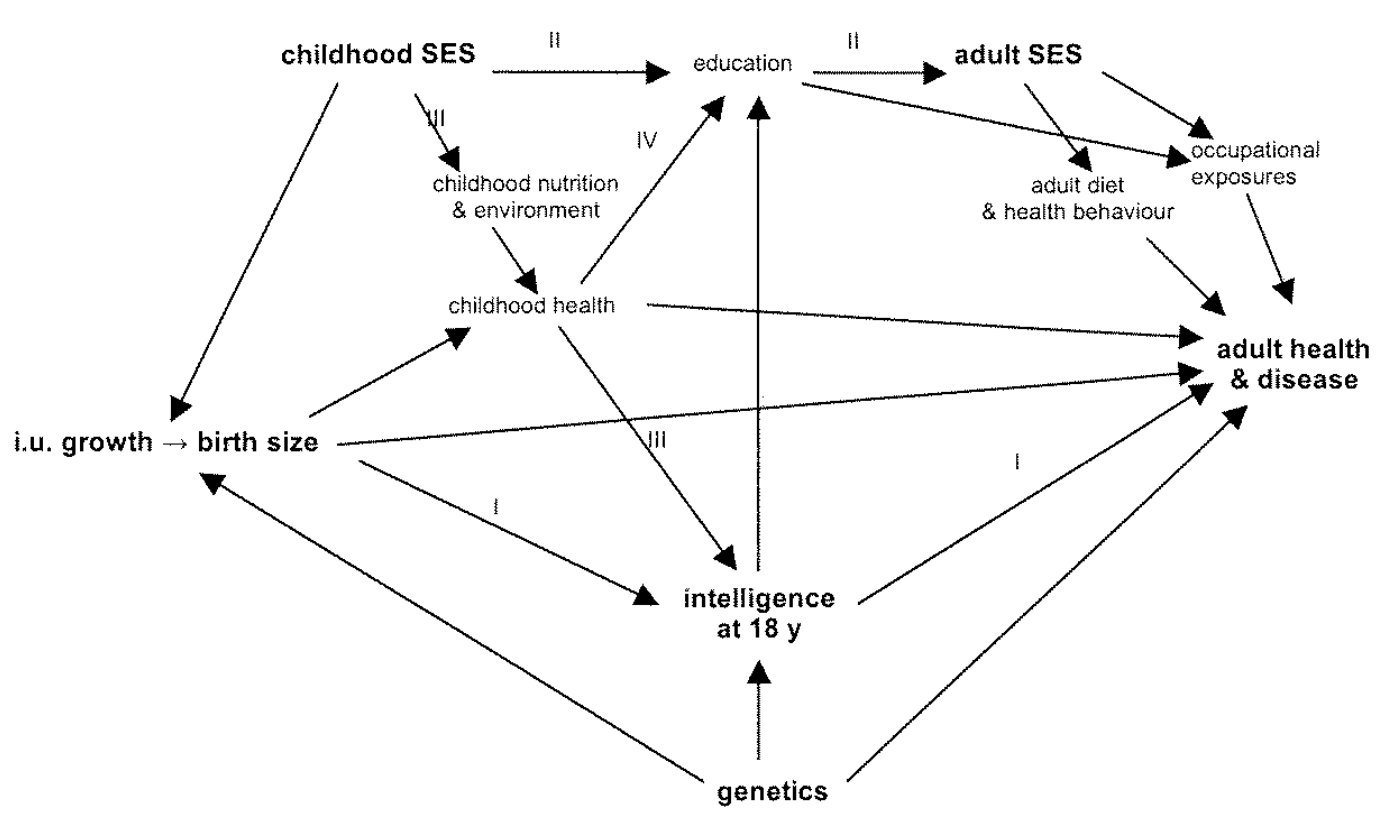

Figure 1. The potential pathways mediating the associations between perinatal conditions, intellectual performance and adult health outcome. ( $\mathrm{SES}=$ socioeconomic status). 
Birth weight

Due to its availability from existing records (or recall in some instances), birth weight has been the most widely studied variable of birth size in retrospective studies regarding early origins of adult disease. The possible association between birth weight and subsequent blood pressure has been extensively studied; however, a recent review summarizes that birth weight is of little relevance to blood pressure in later life. ${ }^{38}$ Birth weight has been found to be inversely associated with risk of type 2 diabetes, ${ }^{36}$ as well as with future gestational diabetes risk in women. ${ }^{41}$ Low birth weight in combination with high body mass index later in life is associated with the highest risk of cardiovascular disease and type 2 diabetes. ${ }^{43}$ Insulin plays a central role in the regulation of foetal growth, and one foetal adaptation to undernutrition is alteration of insulin and glucose metabolism. Thus, foetal adaptation may involve insulin resistance found in patients with type 2 diabetes. Furthermore, several studies have demonstrated positive associations between birth weight and hormone-related cancers, including breast ${ }^{44}$ and testicle, ${ }^{45}$ whereas the association with prostate cancer risk is unclear. ${ }^{46}$ The associations between birth weight and breast or testicular cancer have been hypothesized to be mediated through a high intrauterine oestrogen environment, or similar endocrine mechanisms. ${ }^{44}$ However, the evidence of an association between birth weight and testicular cancer has been weakened by one study that showed no association. ${ }^{47}$

Birth weight is positively associated with height in adulthood. ${ }^{4-51}$ Moreover, birth weight is positively associated with weight later in life. ${ }^{4,51-53}$ Several studies have found that high birth weight is associated with increased risk of obesity in childhood and adulthood. ${ }^{49,53,54}$ On the other hand, low birth weight is associated with central obesity. ${ }^{55}$ Evidence exists that breastfeeding protects against adult obesity. ${ }^{54}$ Children who are overweight tend to become overweight adults. ${ }^{56}$ Thus, growth in foetal life, as well as in infancy, childhood and adolescence, may have a lasting influence on obesity in adulthood. ${ }^{54,56,57}$ Both biological and social pathways may explain this relationship. Higher birth weight is linked to gestational diabetes and maternal obesity or weight gain during pregnancy. Gestational diabetes implies foetal exposure to hyperglycaemia and thus altered glucose-insulin metabolism, which in turn may lead to increased risk of obesity later in life. On the other hand, maternal obesity, which is associated with higher birth weight and also with later obesity in offspring, ${ }^{57}$ may reflect a postnatal environment with unfavourable dietary and activity habits. Moreover, inherited genes for obesity could explain the association between maternal obesity, high birth weight and subsequent obesity in the offspring.

Malnutrition in early foetal life may have adverse effects on the developing brain. ${ }^{58}$ Many studies have addressed this issue by use of birth weight as an indicator of foetal nutrition and intelligence tests at different ages as outcome measures. Most studies have found a positive association between birth weight and intellectual performance extending from the very low birth weights through the normal birth weight range, ${ }^{59-}$

${ }^{66}$ whereas in some studies such an association has not been observed. ${ }^{67,68}$

\section{Birth length}

The literature is scarce on studies of associations of birth length with adult health and disease. However, although not confirmed in later studies, shortness at birth was reported to be associated with adult high blood pressure in a study by Barker et al. ${ }^{69}$ A Finnish study demonstrated an inverse association between length at birth and type 2 diabetes, ${ }^{70}$ whereas a recent Norwegian study found an increased risk of colorectal cancer among men who were short at birth. ${ }^{71}$ Further, birth length has been found to be a strong predictor of adult height; even stronger than birth weight. ${ }^{48,50-52,72,73}$ Also, a positive association seems to exist between birth length and weight in later life, although hardly evaluated. $^{48,51-53}$ However, it is unclear whether length and weight at birth contribute independently to adult body size.

Some studies on the association between birth size and cognitive function have included measures of birth length. ${ }^{59-61,63,67,74}$ In most studies ${ }^{59,60,63,74}$ birth length has been positively associated with intellectual performance, whereas in two studies ${ }^{61,67}$ birth length was not significantly related to intellectual performance.

\section{Gestational age}

Preterm birth is a major cause of perinatal mortality and morbidity, and of long-term neurological problems. ${ }^{64,75}$ Literature is scarce on associations of gestational age with adult health and disease, and most studies are from periods when relatively few preterm infants survived. Still, short gestational age has been associated with increased risk of both testicular ${ }^{47}$ and prostate cancers, ${ }^{46}$ whereas no consistent association with risk of breast cancer has been observed., ${ }^{3,76}$

A study of Swedish conscripts reported that mean height at conscription was positively associated with gestational age until term, and infants born at a gestational age below 32 weeks had a more than twofold increase in the risk for short adult stature compared to those born at term. ${ }^{51}$ This study also found a positive association between gestational age and adult weight. These findings indicate that gestational age influences the association between birth size and adult size, and that gestational age must be adjusted for when evaluating these associations. The number of preterm births in the Swedish study allowed only three broad categories of gestational age. Thus, further research is required to further assess the influence of gestational age on these associations.

In a study from 1967, Barker and Edwards found that a shortened or prolonged period of gestation was associated with impaired intellectual performance in 
11-year-old schoolchildren. ${ }^{77}$ Comparisons between sibs in the same study made the authors suggest that in some cases, impaired performance might be a direct consequence of birth before or after term. Higher risks of impaired intellectual performance among pre- and post-term births have also been observed in more recent studies. $59,61,63,74$

\section{Breech delivery}

Infants born after breech presentation have increased perinatal mortality and higher risk of neonatal complications, ${ }^{78}$ either as a result from underlying conditions that cause breech presentation, ${ }^{79}$ or from damage to the infant during delivery. ${ }^{78,80}$

Although there is an increasing amount of data available on the immediate perinatal outcomes, the long-term outcome after breech delivery has not been extensively studied. A few studies exist on outcomes in childhood, partly indicating an increased risk of handicap or health problems among breech infants, ${ }^{81,82}$ whereas there is a paucity of information on long-term outcomes with follow-up until late adolescence and adulthood.

Intelligence tests may provide functional information about neurodevelopmental morbidity following cerebral damage after breech birth. Two studies have failed to observe any effect of breech presentation or delivery method on intellectual performance, ${ }^{83,84}$ whereas a third observed impaired cognitive function among breech infants. ${ }^{85}$

\section{Socioeconomic factors and health}

There is a strong association between adult SES and health outcomes, and evidence exists that childhood SES has an effect which is additional to that of adult SES. ${ }^{3,86,87}$ Both childhood and adult SES are associated with all-cause mortality and with cardiovascular mortality and morbidity. ${ }^{86,88}$ Furthermore, adverse pregnancy outcomes such as perinatal and infant mortality, low birth weight, intrauterine growth retardation, and preterm birth are associated with socioeconomic disadvantage. ${ }^{89,90}$

There are at least three possible mechanisms for the social inequalities in health: first that health influences SES, second that SES influences health, and, third, that a common factor influences both health and SES. Heredity may be a common factor which may influence both health and SES, for example through genetic contributions to intelligence. Consequently, a personal characteristic, such as intelligence, could determine both SES and health.

Behavioural determinants such as smoking, physical activity, and diet, vary by SES, and access and response to health care services are affected by social and economic capacity. Behavioural determinants and psychosocial characteristics, as well as poor health, cluster in low socioeconomic groups. Low SES is also associated with fewer educational opportunities, limiting the access to jobs and other social resources. It is well known that conditions of work affect level of exposure to physical and psychological hazards. The associations between SES, perinatal risk factors and adult health outcomes imply that adjustment for socioeconomic factors is mandatory.

\section{Background of the present study}

Numerous epidemiologic studies on early origins of adult disease have focused on morbidity among people in middle age or older. However, to understand the mechanisms involved, events occurring between birth and middle age must be taken into account. Thus, evaluation of intermediate health outcomes at younger ages will add to the existing knowledge.

Although Scandinavian studies exist on associations between perinatal variables and height, weight and intelligence at conscription exist, they have certain limitations. For example, in studies from Denmark, the study population was relatively small ( $n$ less than 4500). Moreover, the description of eligible births in the cohort was unclear, implying a possible selection bias. $^{49,60,72,85}$ The Swedish studies included larger samples, but suffered from inadequate control of confounding by SES when evaluating the association between birth size and intelligence. ${ }^{59,63,74}$ Further, despite the relatively large sample sizes, the number of preterm births was relatively low. ${ }^{51}$ Except from a study including less than 500 conscripts, ${ }^{91}$ no large Norwegian study addressing perinatal risk factors and health in early adulthood has been published. The objectives of the two papers referred to in this article were to examine birth length, birth weight, and gestational age as predictors of adult height and weight, and to evaluate the effects of breech birth on adult intellectual performance.

\section{MATERIAL AND METHODS}

In Norway, all births are registered in the Medical Birth Registry of Norway. ${ }^{92}$ Military service is mandatory for all male inhabitants, and draft board data are recorded by the Norwegian Conscripts Service. Men registered in the National Health Insurance Office as being permanently disabled are exempted from military service. Their medical diagnoses were released by the National Health Insurance Office. Moreover, data on emigration and deaths were obtained through regular updating of the National Health Insurance Office to the Population Registry. Record linkage to Statistics Norway provided data from The Cause of Death Registry, and The Register of Level of Education.

\section{Study population}

All singleton male infants live born in Norway during the 13 year period 1967 through 1979 and registered as Norwegian citizens, were included. Among the 393,570 male live births registered in this period, 4,833 (1.2\%) died before age one, 3,550 (0.9\%) died 
between age one and military draft, and 3,788 (1.0\%) emigrated. In the birth cohorts included, 5,692 (1.4\%) had at least one International Classification of Diseases, $9^{\text {th }}$ Revision diagnosis indicating disability. Another 24,355 (6.2\%) were untraceable due to lack of record linkage for individuals born on the $29^{\text {th }}, 30^{\text {th }}$, and $31^{\text {st }}$ of each month. Altogether, 351,352 (89.3\%) male conscripts with draft board medical data were identified in the Norwegian Conscripts Service during the period 1984-1999. Analyses were either restricted to conscripts with measurements of both weight and height ( $n=348,706$ or $88.6 \%$ of the total birth cohort), or to conscripts with data on intelligence testing and maternal educational level $(n=317,761$ or $80.7 \%)$ (Figure 2).

\section{Variables}

Height, weight, and intellectual performance, obtained from the Conscript Service, were the outcome variables. All exposure variables; i.e. birth weight, birth length, gestational age, presentation and delivery mode, were obtained from the Medical Birth Registry, as were confounding variables, except maternal educational level, which was obtained from Statistics Norway. Detailed descriptions of the variables and statistical methods are given in each paper., ${ }^{4,5}$

\section{Ethical approval}

The study was cleared by the Regional Committee for Medical Research Ethics Review and approved by the Norwegian Board of Health and the Data Inspectorate.

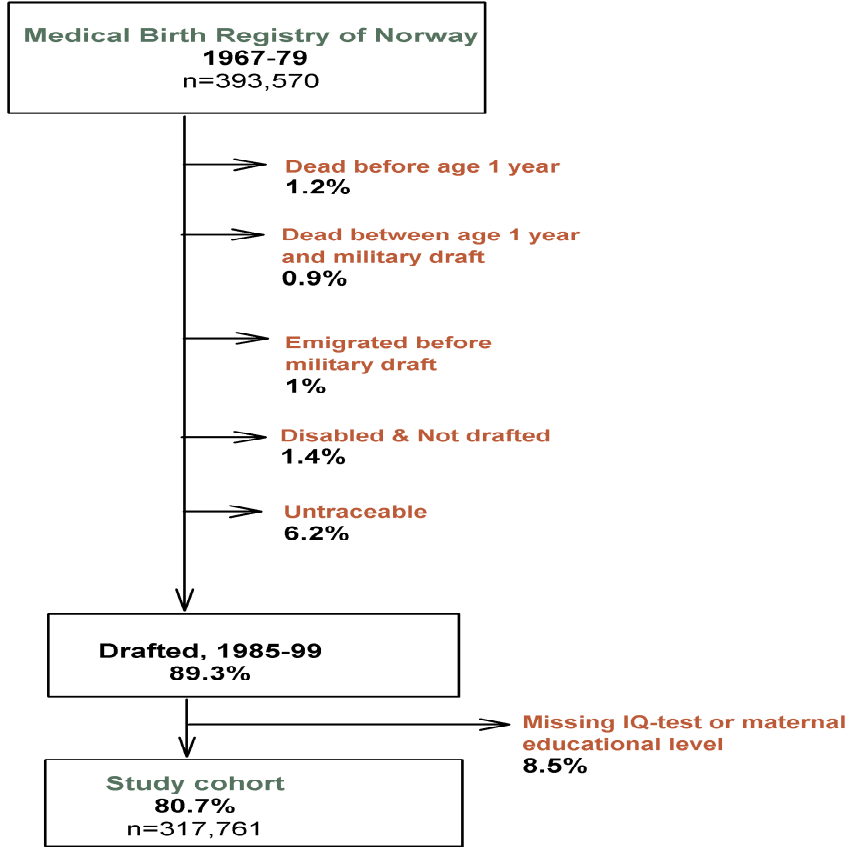

Figure 2. Follow-up diagram of singleton live male births in Norway, 1967-1979.

\section{RESULTS AND DISCUSSION}

\section{Size at birth and adult body size}

In our study, ${ }^{4}$ a linear increase was observed in mean height at conscription by increasing birth length from $46 \mathrm{~cm}$, whereas birth lengths below $46 \mathrm{~cm}$ represented mainly preterm births, and were only weakly associated with adult height. An association between birth length and adult height has also been shown in previous studies. ${ }^{48,72,73}$ Furthermore, we confirmed a positive association between birth length and adult weight, as has been shown in some studies. ${ }^{4,51-53}$

We observed an incremental increase in mean adult height by increasing birth weight, which is in agreement with previous studies. ${ }^{48-51}$ Our results also confirmed that adult weight increased by birth weight; ${ }^{48,51-53}$ although not for birth weights below $2500 \mathrm{~g}$, which comprise a high proportion of preterm births.

The main question in our study was whether length and weight at birth contribute independently to adult height and weight, or if the observed isolated associations were due to the strong interrelations between the birth size variables and gestational age. The paper addresses this issue by use of stratified analyses, gestational age specific z-scores for birth length or birth weight, and standardization on birth length within categories of birth weight and vice versa. We found that length at birth contributed to adult height independent of birth weight and gestational age, and birth weight added to the effect of birth length. Likewise, birth weight contributed independently to adult weight. Birth length added to the effect of birth weight, except for a strong interaction between birth weight and length on adult weight among the long infants. Thus, long and heavy infants became particularly heavy as adults. The latter finding is in agreement with Rasmussen and Johansson. ${ }^{53}$ A Finnish study of twins found highest risk of being overweight among heavy infants of average length, but still they also observed an increased risk among those being both long and heavy. ${ }^{48}$

In our study, birth length explained $7-9 \%$ of the variation in adult height, whereas $0.1-2 \%$ of the variation of adult weight could be explained by birth weight. Thus, the association between birth length and height was stronger than between birth weight and weight. In comparison, a study evaluating effects of preeclampsia on growth into adulthood, estimated that birth length explained $12.6 \%$ of the variance in final height. ${ }^{93}$ In that study, the variance in adult body mass index explained by birth weight was clearly lower, but reported together with other factors. This cannot be directly compared to our results, but is supportive of our interpretation; namely that the contribution of birth length to adult height was rather small, and the contribution of birth weight to adult weight was even smaller. Thus, assuming that height and weight in young adulthood are related to health outcomes later in life, prenatal factors may have influences on health outcomes; however there is reason to believe that other 
factors working through the life course are more critical.

The contribution of gestational age and preterm birth to the birth size-adult size association was an important concern in our paper. Whereas several studies have included only full term subjects, ${ }^{11,50,73,94}$ some studies including preterms have had limited ability to evaluate gestational age effects due to low numbers of preterm births. ${ }^{51,52,72}$ A few studies have investigated the effects of gestational age on the birth size-adult size association. We found that gestational age above 37 weeks had no effect on this association, consistent with Leger et al. ${ }^{73}$ This is also supported by Tuvemo et al. ${ }^{51}$ who concluded that except in very preterm births, gestational age has a limited impact on final height. Our study confirmed the findings of Tuvemo et al. ${ }^{51}$ and Lundgren et al. ${ }^{52}$ indicating that being short for gestational age was associated with short stature in adulthood. Also, our study demonstrated that the relation between birth length and adult stature was weaker among preterm than term births. A possible interpretation is that birth size in preterm infants reflects the growth potential to a smaller extent than in term infants.

As adult stature may be associated with disease, underlying shared factors predicting birth length, adult height, and disease later in life, are likely. This study demonstrated that birth length was a stronger predictor of adult body size than birth weight which has been the key variable in studies on early origins of adult diseases. Therefore, when considering size at birth, birth length may be considered as a better predictor of adult morbidity and mortality than birth weight.

\section{Breech delivery and intelligence}

\section{Presentation at birth}

Our study did not show any difference in intellectual performance between male conscripts delivered in breech compared with cephalic presentation $(\mathrm{P}=0.3) .^{5}$ This is in line with the findings in two studies, one Australian and one Norwegian, published in 1979 and 1985 , respectively. ${ }^{83,84}$ In contrast to our results, a study of Danish conscripts suggested impaired cognitive outcome after breech presentation. ${ }^{85}$ A Finnish historical cohort study from 2004 evaluated long-term outcome in terms of need for special education at the age of 9 years. No difference between breech and cephalic births was observed. ${ }^{95}$ Compared with these previous studies, strengths of the present study are its large sample size of breech births, the fact that it is nationwide and also the high degree of follow-up.

\section{Delivery mode}

We could not demonstrate an adverse intellectual outcome after vaginal breech delivery compared with caesarean section. This is consistent with previous studies of relatively small samples. ${ }^{84,85,95,96}$ Since data on whether a caesarean delivery was elective or emer- gency were not recorded during the period our study infants were born, we could not disentangle possible hazards of emergency delivery. Cohort studies are criticized for being flawed by confounding by indication; i.e. that factors which influence the choice of mode of delivery may be more decisive as to the outcome for the baby than the mode of delivery. ${ }^{79}$ Such data were unavailable in our study; however, since the vaginal breech group comprised the vast majority of births, confounding by indication probably would not change the results with regard to the lack of adverse effects of vaginal delivery.

For cephalic births in our study, caesarean section was associated with a significantly lower score, consistent with two previous studies. ${ }^{85,97}$ However, the possibility of confounding by indication is particularly relevant when comparing delivery mode among cephalic births, and should be further evaluated.

\section{Methods of vaginal delivery}

We found that intellectual performance was similar when comparing delivery by either forceps to the aftercoming head or breech extraction to the assisted breech delivery. No previous study has compared methods of breech vaginal births. In a study by Roemer et al. such analyses could not be done because the birth records rarely differentiated between methods of vaginal delivery. ${ }^{98}$

In analyses restricted to birth weights $3000 \mathrm{~g}$ and above, we found no differences when comparing forceps delivery, vacuum extraction or shoulder dystocia with uncomplicated delivery. Some studies have evaluated intellectual outcome in cephalic vaginal births. ${ }^{97-100}$ In two of these studies there was an association between instrumental vaginal delivery and higher intelligence test scores, ${ }^{98,99}$ whereas in two studies there was no significant difference between spontaneous and instrumental delivery. ${ }^{97,100}$ Except for the study by Seidman et al., ${ }^{97}$ these studies include small samples, and may also suffer from biases due to selection and confounding factors.

Evaluation of confounding by birth weight was a major concern in our paper. Gestational age and birth length was evaluated as confounders, however, due to the high interrelation between these variables, controlling for birth weight turned out to be appropriate. Because breech delivery is associated with being small for gestational age and preterm delivery, the birth weight distribution for breech infants was shifted towards the left. This also applied to the study cohort of conscripts born in breech as compared to cephalic presentation. Due to their lower birth weights, infants to the left should be at the highest risk of adverse perinatal outcomes. However, several studies have shown that these infants may fare better than would be expected due to their higher risk, a phenomenon recognized in perinatal epidemiology as the 'low birth weight paradox'. ${ }^{101,102}$ Consequently, adjusting for birth weight introduced an artefact resulting in a more favourable 
outcome for the breech group in which mean birth weight was lowest.

\section{Socioeconomic factors}

In Scandinavia, differences between social levels are small, and access to health care is practically independent of social class. ${ }^{103}$ Nevertheless, socioeconomic differences do exist, and these differences have implications for perinatal health. ${ }^{103}$ Also, inequalities in adult health are relatively large, despite an egalitarian policy. ${ }^{104}$ A possible explanation may be that the egalitarian policy has had a stronger influence on income related inequalities of health than in differences according to education. ${ }^{104}$ Moreover, improvements in a country's overall health are often followed by larger social class inequalities in health. ${ }^{29}$ This is probably because the improvements are smaller among those who have low education and low income than among those who have high education and better income. Education reflects personal resources, such as knowledge and competence, and is not only a proxy for standard of living. Hence, education may influence health through differences in values, life-style behaviours, and problem-solving abilities. ${ }^{105}$

In our study, the associations between birth size and adult size were not substantially influenced by adjustment for proxies of SES, i.e. maternal age, parity and marital status. Supportive of this rather robust association, Emanuel et al. ${ }^{106}$ have argued, based on their findings in an intergenerational study, that the growth status of the individual is more important than the socioeconomic circumstances for the associations of birth size and adult height with chronic diseases.

Maternal education and other confounders accounted for the higher risks associated with breech delivery. This may imply that the increased perinatal risks on long-term outcomes are exceeded by influences of SES. Thus, since SES may modify the impact of early life exposures on adult health, adult diseases may be best focused on in a life course perspective. ${ }^{34,107}$ Furthermore, this entails a potential for intervention programmes directed towards the social inequalities in health.

\section{Strengths and limitations}

Strengths of our study were the large sample size, the longitudinal design, and the fact that $94 \%$ of the cohort was traced until age 18 years. The historical cohort design is well suited for evaluating the impact of foetal growth on adult health. However, the study comprises only two observations acting in a very specific time window, and no data on other periods of the life course were available.

Despite the high degree of follow-up, selection bias may affect the validity of the study. Altogether, $89.3 \%$ of the birth cohort was identified with draft board data. Accordingly, such data were missing for $10.7 \%$ of the birth cohort due to deaths, permanent disability, or emigration before military draft. In addition, a number of men were untraceable due to a technical problem that caused lack of record linkage for all individuals born on the $29^{\text {th }}, 30^{\text {th }}$, or $31^{\text {st }}$ of each month, representing a random sample. Selection bias would arise only if the association between perinatal risk and outcome differed between those studied and those lost to follow-up. The proportion of preterm and low birth weight infants was higher among those lost to followup as compared to those who made it to the draft board. If non-appearance before the draft board was associated with shorter height, the observed mean height in our study would be higher than the true value; accordingly, the true associations might be stronger than we observed. Also, a higher proportion of breech-presented infants never appeared before the draft board. However, intelligence test score for the majority of breech births was available and equal to that of cephalic births despite a lower birth weight among the breech infants; thus it is unlikely that selection bias may explain the finding that breech presentation did not affect intellectual performance.

Non-differential misclassification of both birth and draft board data may be present, and would reduce true associations. Particularly, gestational age, which was based on self-reported last menstrual period, may have been misclassified as too short when bleeding early during pregnancy erroneously was reported as a menstruation. Birth weight was used as a corrective criterion to avoid such misclassification, and infants with z-scores for birth weight outside 3 standard deviations were excluded. Also, although not very likely, breech presentation or caesarean section may in some cases have been classified as cephalic or vaginal deliveries, respectively. Finally, height, weight, and intellectual performance may suffer from measurement errors if the standardized procedures were neglected. However, if conscripts for any reason tried to obtain poor scores on the intelligence test, such cases probably would not be more frequent among the subgroups at risk in this study compared with the reference groups.

In both papers, we included variables to assess SES. There may be other confounders that we have not measured. Particularly, data on parental body size and intelligence were unavailable. Although maternal educational level is a strong proxy of maternal intelligence, residual confounding may still be present.

\section{Conclusions}

This nationwide study shows positive associations between birth weight and length on one hand and adult height and weight on the other. The associations are weak, but extend through the normal range of birth size. An interaction was observed of being long and heavy at birth on adult weight, with long and heavy infants becoming particular heavy as adults. The results suggest that birth length is a stronger predictor 
of adult body size than birth weight. The biological mechanisms that may be involved cannot be established from the present study and need further inves- tigation. Furthermore, the results weaken the hypothesis that breech birth could be associated with impaired intellectual performance in adulthood.

\section{REFERENCES}

1. Barker DJ. Mothers, Babies, and Disease in Later Life. London: BMJ Publishing Group, 1994.

2. Barker DJ. The developmental origins of adult disease. J Am Coll Nutr 2004; 23: 588S-95S.

3. Kuh D, Ben-Shlomo Y. A life course approach to chronic disease epidemiology, 2nd edn. Oxford: Oxford University Press, 2004.

4. Eide MG, Øyen N, Skjærven R, Nilsen ST, Bjerkedal T, Tell GS. Size at birth and gestational age as predictors of adult height and weight. Epidemiology 2005; 16: 175-81.

5. Eide MG, Øyen N, Skjærven R, Irgens LM, Bjerkedal T, Nilsen ST. Breech delivery and intelligence: a population-based study of 8,738 breech infants. Obstet Gynecol 2005; 105: 4-11.

6. Bjerkedal T, Beckstrøm JR, Brevik JI, Skåden K. [Height, weight and body mass index measured among men born 1967-80]. Tidsskr Nor Laegeforen 2001; 121: 674-7.

7. Brundtland GH, Liestol K, Walloe L. Height, weight and menarcheal age of Oslo schoolchildren during the last 60 years. Ann Hum Biol 1980; 7: 307-22.

8. Hirschhorn JN, Lindgren CM, Daly MJ, Kirby A, Schaffner SF, Burtt NP, et al. Genomewide linkage analysis of stature in multiple populations reveals several regions with evidence of linkage to adult height. $\mathrm{Am} \mathrm{J}$ Hum Genet 2001; 69: 106-16.

9. Waaler HT. Height, weight and mortality. The Norwegian experience. Acta Med Scand Suppl 1984; 679: 156.

10. Engeland A, Bjørge T, Selmer RM, Tverdal A. Height and body mass index in relation to total mortality. Epidemiology 2003; 14: 293-9.

11. Karlberg J, Luo ZC. Foetal size to final height. Acta Paediatr 2000; 89: 632-6.

12. Leon DA, Smith GD, Shipley M, Strachan D. Adult height and mortality in London: early life, socioeconomic confounding, or shrinkage? J Epidemiol Community Health 1995; 49: 5-9.

13. Peck AM, Vagerø DH. Adult body height, self perceived health and mortality in the Swedish population. $J$ Epidemiol Community Health 1989; 43: 380-4.

14. Bjørge T, Tretli S, Engeland A. Relation of height and body mass index to renal cell carcinoma in two million Norwegian men and women. Am J Epidemiol 2004; 160: 1168-76.

15. Bielicki T, Charzewski J. Body height and upward social mobility. Ann Hum Biol 1983; 10: 403-8.

16. Calle EE, Thun MJ, Petrelli JM, Rodriguez C, Heath CW, Jr. Body-mass index and mortality in a prospective cohort of U.S. adults. N Engl J Med 1999; 341: 1097-105.

17. Calle EE, Rodriguez C, Walker-Thurmond K, Thun MJ. Overweight, obesity, and mortality from cancer in a prospectively studied cohort of U.S. adults. N Engl J Med 2003; 348: 1625-38.

18. Gortmaker SL, Must A, Perrin JM, Sobol AM, Dietz WH. Social and economic consequences of overweight in adolescence and young adulthood. $N$ Engl J Med 1993; 329: 1008-12.

19. Willett WC, Dietz WH, Colditz GA. Guidelines for healthy weight. N Engl J Med 1999; 341: 427-34.

20. Jung RT. Obesity as a disease. Br Med Bull 1997; 53: 307-21.

21. IARC Working Group on the Evaluation of Cancer Preventive Strategies. Weight Control and Physical Activity. Lyon: IARC Press, International Agency for Research on Cancer, 2002.

22. Gottfredson L. Maintream science on intellignece: An editorial with 52 signatories, history, and bibliography. Intelligence 1997; 24: 13-23.

23. Whalley LJ, Deary IJ. Longitudinal cohort study of childhood IQ and survival up to age 76. BMJ 2001; 322: 819.

24. Kuh D, Richards M, Hardy R, Butterworth S, Wadsworth ME. Childhood cognitive ability and deaths up until middle age: a post-war birth cohort study. Int J Epidemiol 2004; 33: 408-13.

25. Osler M, Andersen AM, Due P, Lund R, Damsgaard MT, Holstein BE. Socioeconomic position in early life, birth weight, childhood cognitive function, and adult mortality. A longitudinal study of Danish men born in 1953. J Epidemiol Community Health 2003; 57: 681-6.

26. Batty GD, Deary IJ. Early life intelligence and adult health. BMJ 2004; 329: 585-6.

27. Gunnell D, Magnusson PK, Rasmussen F. Low intelligence test scores in 18 year old men and risk of suicide: cohort study. BMJ 2005; 330: 167.

28. Deary IJ, Whiteman MC, Starr JM, Whalley LJ, Fox HC. The impact of childhood intelligence on later life: following up the Scottish mental surveys of 1932 and 1947. J Pers Soc Psychol 2004; 86: 130-47. 
29. Gottfredson LS. Intelligence: is it the epidemiologists' elusive "fundamental cause" of social class inequalities in health? J Pers Soc Psychol 2004; 86: 174-99.

30. Singh-Manoux A, Ferrie JE, Lynch JW, Marmot M. The Role of Cognitive Ability (Intelligence) in Explaining the Association between Socioeconomic Position and Health: Evidence from the Whitehall II Prospective Cohort Study. Am J Epidemiol 2005; 161: 831-9.

31. Forsdahl A. Are poor living conditions in childhood and adolescence an important risk factor for arteriosclerotic heart disease? Br J Prev Soc Med 1977; 31: 91-5.

32. Barker DJ. Fetal origins of coronary heart disease. BMJ 1995; 311: 171-4.

33. Lucas A. Programming by early nutrition in man. Ciba Found Symp 1991; 156: 38-50.

34. Ben-Shlomo Y, Kuh D. A life course approach to chronic disease epidemiology: conceptual models, empirical challenges and interdisciplinary perspectives. Int J Epidemiol 2002; 31: 285-93.

35. Singhal A, Lucas A. Early origins of cardiovascular disease: is there a unifying hypothesis? Lancet 2004; 363: $1642-5$.

36. Leon DA. Fetal growth and adult disease. Eur J Clin Nutr 1998; 52: S72-8.

37. Joseph KS, Kramer MS. Review of the evidence on fetal and early childhood antecedents of adult chronic disease. Epidemiol Rev 1996; 18: 158-74.

38. Huxley R, Neil A, Collins R. Unravelling the fetal origins hypothesis: is there really an inverse association between birthweight and subsequent blood pressure? Lancet 2002; 360: 659-65.

39. Gillman MW, Rich-Edwards JW. The fetal origin of adult disease: from sceptic to convert. Paediatr Perinat Epidemiol 2000; 14: 192-3.

40. Gillman MW. Epidemiological challenges in studying the fetal origins of adult chronic disease. Int $J$ Epidemiol 2002; 31: 294-9.

41. Egeland GM, Skjærven R, Irgens LM. Birth characteristics of women who develop gestational diabetes: population based study. BMJ 2000; 321: 546-7.

42. Rich-Edwards JW, Kleinman K, Michels KB, Stampfer MJ, Manson JE, Rexrode KM, Hibert EN, Willett WC. Longitudinal study of birth weight and adult body mass index in predicting risk of coronary heart disease and stroke in women. BMJ 2005; 330: 1115.

43. Godfrey KM, Barker DJ. Fetal nutrition and adult disease. Am J Clin Nutr 2000; 71: 1344S-52S.

44. Trichopoulos D. Hypothesis: does breast cancer originate in utero? Lancet 1990; 335: 939-40.

45. Møller H, Skakkebæk NE. Testicular cancer and cryptorchidism in relation to prenatal factors: case-control studies in Denmark. Cancer Causes Control 1997; 8: 904-12.

46. Ekbom A, Wuu J, Adami HO, Lu CM, Lagiou P, Trichopoulos D, Hsieh C. Duration of gestation and prostate cancer risk in offspring. Cancer Epidemiol Biomarkers Prev 2000; 9: 221-3.

47. Weir HK, Marrett LD, Kreiger N, Darlington GA, Sugar L. Pre-natal and peri-natal exposures and risk of testicular germ-cell cancer. Int J Cancer 2000; 87: 438-43.

48. Pietilainen KH, Kaprio J, Rasanen M, Winter T, Rissanen A, Rose RJ. Tracking of body size from birth to late adolescence: contributions of birth length, birth weight, duration of gestation, parents' body size, and twinship. Am J Epidemiol 2001; 154: 21-9.

49. Sørensen HT, Sabroe S, Rothman KJ, Gillman M, Fischer P, Sørensen TI. Relation between weight and length at birth and body mass index in young adulthood: cohort study. BMJ 1997; 315: 1137.

50. Karlberg J, Albertsson-Wikland K. Growth in full-term small-for-gestational-age infants: from birth to final height. Pediatr Res 1995; 38: 733-9.

51. Tuvemo T, Cnattingius S, Jonsson B. Prediction of male adult stature using anthropometric data at birth: a nationwide population-based study. Pediatr Res 1999; 46: 491-5.

52. Lundgren EM, Cnattingius S, Jonsson B, Tuvemo T. Prediction of adult height and risk of overweight in females born small-for-gestational-age. Paediatr Perinat Epidemiol 2003; 17: 156-63.

53. Rasmussen F, Johansson M. The relation of weight, length and ponderal index at birth to body mass index and overweight among 18-year-old males in Sweden. Eur J Epidemiol 1998; 14: 373-80.

54. Martorell R, Stein AD, Schroeder DG. Early nutrition and later adiposity. J Nutr 2001; 131: 874S-880S.

55. Kuh D, Hardy R, Chaturvedi N, Wadsworth ME. Birth weight, childhood growth and abdominal obesity in adult life. Int J Obes Relat Metab Disord 2002; 26: 40-7.

56. Whitaker RC, Wright JA, Pepe MS, Seidel KD, Dietz WH. Predicting obesity in young adulthood from childhood and parental obesity. N Engl J Med 1997; 337: 869-73.

57. Kvaavik E, Tell GS, Klepp KI. Predictors and tracking of body mass index from adolescence into adulthood: follow-up of 18 to 20 years in the Oslo Youth Study. Arch Pediatr Adolesc Med 2003; 157: 1212-8.

58. Morgane PJ, Austin-LaFrance R, Bronzino J, Tonkiss J, Diaz-Cintra S, Cintra L, Kemper T, Galler JR. Prenatal malnutrition and development of the brain. Neurosci Biobehav Rev 1993; 17: 91-128.

59. Lundgren EM, Cnattingius S, Jonsson B, Tuvemo T. Intellectual and psychological performance in males born small for gestational age with and without catch-up growth. Pediatr Res 2001; 50: 91-6. 
60. Sørensen HT, Sabroe S, Olsen J, Rothman KJ, Gillman MW, Fischer P. Birth weight and cognitive function in young adult life: historical cohort study. BMJ 1997; 315: 401-3.

61. Shenkin SD, Starr JM, Pattie A, Rush MA, Whalley LJ, Deary IJ. Birth weight and cognitive function at age 11 years: the Scottish Mental Survey 1932. Arch Dis Child 2001; 85: 189-96.

62. Richards M, Hardy R, Kuh D, Wadsworth ME. Birth weight and cognitive function in the British 1946 birth cohort: longitudinal population based study. BMJ 2001; 322: 199-203.

63. Lundgren EM, Cnattingius S, Jonsson B, Tuvemo T. Intellectual and psychological performance in males born small for gestational age. Horm Res 2003; 59 Suppl 1: 139-41.

64. Hack M, Flannery DJ, Schluchter M, Cartar L, Borawski E, Klein N. Outcomes in young adulthood for verylow-birth-weight infants. N Engl J Med 2002; 346: 149-57.

65. Jefferis BJ, Power C, Hertzman C. Birth weight, childhood socioeconomic environment, and cognitive development in the 1958 British birth cohort study. BMJ 2002; 325: 305.

66. Shenkin SD, Starr JM, Deary IJ. Birth weight and cognitive ability in childhood: a systematic review. Psychol Bull 2004; 130: 989-1013.

67. Martyn CN, Gale CR, Sayer AA, Fall C. Growth in utero and cognitive function in adult life: follow up study of people born between 1920 and 1943. BMJ 1996; 312: 1393-6.

68. Pearce MS, Deary IJ, Young AH, Parker L. Growth in early life and childhood IQ at age 11 years: the Newcastle Thousand Families Study. Int J Epidemiol 2005; 34: 673-7.

69. Barker DJ, Godfrey KM, Osmond C, Bull A. The relation of fetal length, ponderal index and head circumference to blood pressure and the risk of hypertension in adult life. Paediatr Perinat Epidemiol 1992; 6: 35-44.

70. Forsen T, Eriksson J, Tuomilehto J, Reunanen A, Osmond C, Barker D. The fetal and childhood growth of persons who develop type 2 diabetes. Ann Intern Med 2000; 133: 176-82.

71. Nilsen TI, Romundstad PR, Troisi R, Potischman N, Vatten LJ. Birth size and colorectal cancer risk: a prospective population-based study. Gut 2005; 54: 1728-32.

72. Sørensen HT, Sabroe S, Rothman KJ, Gillman M, Steffensen FH, Fischer P, Sørensen TI. Birth weight and length as predictors for adult height. Am J Epidemiol 1999; 149: 726-9.

73. Leger J, Limoni C, Collin D, Czernichow P. Prediction factors in the determination of final height in subjects born small for gestational age. Pediatr Res 1998; 43: 808-12.

74. Lundgren EM, Cnattingius S, Jonsson B, Tuvemo T. Birth characteristics and different dimensions of intellectual performance in young males: a nationwide population-based study. Acta Paediatr 2003; 92: 1138-43.

75. Markestad T, Kaaresen PI, Ronnestad A, Reigstad H, Lossius K, Medbo S, et al. Early death, morbidity, and need of treatment among extremely premature infants. Pediatrics 2005; 115: 1289-98.

76. Michels KB, Trichopoulos D, Robins JM, Rosner BA, Manson JE, Hunter DJ, et al. Birthweight as a risk factor for breast cancer. Lancet 1996; 348: 1542-6.

77. Barker DJ, Edwards JH. Obstetric complications and school performance. BMJ 1967; 3: 695-9.

78. Gilbert WM, Hicks SM, Boe NM, Danielsen B. Vaginal versus cesarean delivery for breech presentation in California: a population-based study. Obstet Gynecol 2003; 102: 911-7.

79. Hofmeyr GJ, Hannah ME. Planned caesarean section for term breech delivery (Cochrane Review). In: The Cochrane Library, Issue 3, 2003. Oxford: Update Software.

80. Hannah ME, Hannah WJ, Hewson SA, Hodnett ED, Saigal S, Willan AR. Planned caesarean section versus planned vaginal birth for breech presentation at term: a randomised multicentre trial. Term Breech Trial Collaborative Group. Lancet 2000; 356: 1375-83.

81. Danielian PJ, Wang J, Hall MH. Long-term outcome by method of delivery of fetuses in breech presentation at term: population based follow up. BMJ 1996; 312: 1451-3.

82. Pradhan P, Mohajer M, Deshpande S. Outcome of term breech births: 10 -year experience at a district general hospital. BJOG 2005; 112: 218-22.

83. Nilsen ST, Bergsjø P. Males born in breech presentation 18 years after birth. Acta Obstet Gynecol Scand 1985; 64: 323-5.

84. McBride WG, Black BP, Brown CJ, Dolby RM, Murray AD, Thomas DB. Method of delivery and developmental outcome at five years of age. Med J Aust 1979; 1: 301-4.

85. Sørensen HT, Steffensen FH, Olsen J, Sabroe S, Gillman MW, Fischer P, Rothman KJ. Long-term follow-up of cognitive outcome after breech presentation at birth. Epidemiology 1999; 10: 554-6.

86. Kuh D, Hardy R, Langenberg C, Richards M, Wadsworth ME. Mortality in adults aged 26-54 years related to socioeconomic conditions in childhood and adulthood: post war birth cohort study. BMJ 2002; 325: 1076-80.

87. Luo Y, Waite LJ. The impact of childhood and adult SES on physical, mental, and cognitive well-being in later life. J Gerontol B Psychol Sci Soc Sci 2005; 60: S93-S101.

88. Smith GD, Hart C, Blane D, Hole D. Adverse socioeconomic conditions in childhood and cause specific adult mortality: prospective observational study. BMJ 1998; 316: 1631-5. 
89. Kramer MS, Goulet L, Lydon J, Seguin L, McNamara H, Dassa C, et al. Socio-economic disparities in preterm birth: causal pathways and mechanisms. Paediatr Perinat Epidemiol 2001; 15 Suppl 2: 104-23.

90. Kramer MS, Seguin L, Lydon J, Goulet L. Socio-economic disparities in pregnancy outcome: why do the poor fare so poorly? Paediatr Perinat Epidemiol 2000; 14: 194-210.

91. Nilsen ST. Males with perinatal risk factors examined at 18 years of age (dissertation). Bergen: University of Bergen, 1985.

92. Irgens LM. The Medical Birth Registry of Norway. Epidemiological research and surveillance throughout 30 years. Acta Obstet Gynecol Scand 2000; 79: 435-9.

93. Ros HS, Lichtenstein P, Ekbom A, Cnattingius S. Tall or short? Twenty years after preeclampsia exposure in utero: comparisons of final height, body mass index, waist-to-hip ratio, and age at menarche among women, exposed and unexposed to preeclampsia during fetal life. Pediatr Res 2001; 49: 763-9.

94. Paz I, Seidman DS, Danon YL, Laor A, Stevenson DK, Gale R. Are children born small for gestational age at increased risk of short stature? Am J Dis Child 1993; 147: 337-9.

95. Ulander VM, Gissler M, Nuutila M, Ylikorkala O. Are health expectations of term breech infants unrealistically high? Acta Obstet Gynecol Scand 2004; 83: 180-6.

96. Munstedt K, von Georgi R, Reucher S, Zygmunt M, Lang U. Term breech and long-term morbidity cesarean section versus vaginal breech delivery. Eur J Obstet Gynecol Reprod Biol 2001; 96: 163-7.

97. Seidman DS, Laor A, Gale R, Stevenson DK, Mashiach S, Danon YL. Long-term effects of vacuum and forceps deliveries. Lancet 1991; 337: 1583-5.

98. Roemer FJ, Rowland DY. Long-term developmental outcomes of method of delivery. Early Hum Dev 1994; 39: $1-14$.

99. Nilsen ST. Boys born by forceps and vacuum extraction examined at 18 years of age. Acta Obstet Gynecol Scand 1984; 63: 549-54.

100. Wesley BD, van den Berg BJ, Reece EA. The effect of forceps delivery on cognitive development. Am $J$ Obstet Gynecol 1993; 169: 1091-5.

101. Wilcox A, Russell I. Why small black infants have a lower mortality rate than small white infants: the case for population-specific standards for birth weight. J Pediatr 1990; 116: 7-10.

102. Wilcox AJ. On the importance - and the unimportance - of birthweight. Int J Epidemiol 2001; 30: $1233-41$.

103. Bakketeig LS, Cnattingius S, Knudsen LB. Socioeconomic differences in fetal and infant mortality in Scandinavia. J Public Health Policy 1993; 14: 82-90.

104. Cavelaars AE, Kunst AE, Geurts JJ, Crialesi R, Grotvedt L, Helmert U, et al. Differences in self reported morbidity by educational level: a comparison of 11 western European countries. J Epidemiol Community Health 1998; 52: 219-27.

105. Winkleby MA, Jatulis DE, Frank E, Fortmann SP. Socioeconomic status and health: how education, income, and occupation contribute to risk factors for cardiovascular disease. Am J Public Health 1992; 82: 816-20.

106. Emanuel I, Kimpo C, Moceri V. The association of grandmaternal and maternal factors with maternal adult stature. Int J Epidemiol 2004; 33: 1243-8.

107. Eriksson JG. The fetal origins hypothesis - 10 years on. BMJ 2005; 330: 1096-7. 